\title{
Labor market integration of new immigrants in Spain
}

\author{
Núria Rodríguez-Planas ${ }^{1,2^{*}}$ and Natalia Nollenberger ${ }^{3}$
}

\author{
* Correspondence: \\ nrodriguezplanas@gmail.com \\ ${ }^{1}$ City University of New York \\ (CUNY), Queens College, New York, \\ USA \\ ${ }^{2}$ IZA, Bonn, Germany \\ Full list of author information is \\ available at the end of the article
}

\begin{abstract}
Immigrants' employment status has worsened during the Great Recession in Spain. How much of this worsening is due to the recession, and how much to a composition effect? Using Spanish Labor Force Survey data from 2000 through 2011, we compare the employment trajectories of different cohorts of immigrants and natives and find that those who arrived before the 2008 recession had little trouble finding work immediately. In contrast, those who arrived after 2008 struggled to find work as Spanish unemployment rates skyrocketed. In addition, although many immigrants who arrived in Spain between 2000 and 2007 were able to find work and eventually move out of the low-skilled positions, the nature of their jobs did not shield them from the recession. Hence, many became unemployed as the economy shed low- and middle-skilled jobs in sectors dominated by immigrants. Immigrants' individual characteristics, such as gender, country of origin, or educational level, had a limited effect on their employment trajectories. These findings suggest that for many workers, finding middle-skilled work alone isn't enough. Hence, integration policies could aim to help workers transition from the secondary to the primary labor market in order to find their way into more stable employment.

JEL codes: J15, J24, J61, J62

Keywords: Immigrants, Great recession, Spain
\end{abstract}

\section{Introduction}

Within the first decade of the century, the Spanish economy went from an economic boom-partly driven by the real-estate market-to a double recession that led to 26 percent unemployment rate (the highest in Spanish modern history). During the expansion, many low-qualified jobs were created in the construction, food preparation and serving sectors, as well as in domestic services, at the same time that the country welcomed an impressive inflow of immigrants-approximately 500,000 per year between 2002 and 2007-who were quick to find jobs in the thriving economy. ${ }^{1}$ What was the impact of this recession on the labor market assimilation of workers (relative to native workers)? This is the main objective of this paper.

Using Spanish Labor Force survey data (EPA) from 2000 to 2011 and following three distinct immigrant cohorts-those who arrived between 2000 and 2003 (both included); those who arrived between 2004 and 2007, and those who arrived between 2008 and 2011-, this paper analyzes whether the worsening of immigrants' employment conditions after the Great Recession is explained exclusively by the deterioration of the economy or

\section{Springer}


whether it can be also attributed to a compositional differences across different cohorts of immigrants. Immigrants are defined as foreign-born individuals who are between 18 and 64 years old. ${ }^{2}$

For this purpose, Section 2 studies how newly arrived immigrants assimilate into employment, distinguishing on how economic conditions and immigrants' individual characteristics influence this assimilation pattern. Section 3 evaluates immigrants' pathways from the lowest-skilled jobs into middle-skilled work, with a special emphasis on immigrants who lack high-level education. After investigating in which sectors immigrant workers are concentrated, the paper analyzes the key characteristics of immigrant-heavy sectors in Section 4. Section 5 analyzes whether immigrants' sociodemographic characteristics affect immigrants' labor markets. We conclude with a summary of the key findings and their implications for policymaking.

\section{Immigrants' employment assimilation}

How do newly arrived immigrants' employment rates evolve over time? Have successive cohorts of immigrants who arrived since 2000 fared similarly or have there been differences between them? To study this, Fig. 1 plots the average employment rate for the three cohorts of immigrants under analysis from the year 2000 to the year 2011. In addition, the average employment rate of natives is also plotted as a reference. Panel a in Fig. 1 displays the results from estimating a linear regression where the LHS variable is a dummy variable indicating whether the individual is working or not and the RHS variables are year dummies interacted by cohort. The cohort is defined according to the period of arrival: 20002003; 2004-2007; 2008-2011. Panel b displays the results from estimating a regression in two stages. In the first stage, the LHS variable is a dummy variable indicating whether the individual is employed or not and the RHS variables include individual characteristics (age, sex, married, education level and continent of origin) and the relative stock of immigrants (Immigrants/Total Population). The second stage uses as LHS the predicted probability of employment in the first stage and year dummies as RHS. Each stage was run separately by cohort of immigrants and natives. Panel $\mathrm{c}$ is estimated as in Panel b but replacing individual characteristics and the relative stock of immigrants by the GDP growth and the Unemployment Rate. Comparing Panels a to $\mathrm{b}$ and a to $\mathrm{c}$ will reveal whether differences in the individuals' characteristics explain a differential pattern across cohorts (A to B) as well as whether different cohorts of immigrants react differently to the business cycle (A to C).

\subsection{Raw data}

Focusing on the cohort of immigrants who arrived between 2000 and 2003 in Panel a, we observe that their average employment rate at arrival was 56 percent in 2000 and close to 70 percent between the years 2001 and 2003, higher than the native-born population. By 2006, this share has increased to about 80 percent, on average, indicating that newly arrived immigrants fared quite well in terms of employment both at arrival and thereafter during this period. This is somewhat to be expected in Spain where most immigration is labor-based (Fernández and Ortega 2008). As explained by Rodríguez-Planas 2013, Spain was an attractive destination for immigrants because of its booming economy and large demand for low-skilled workers, but not because of its welfare.

After the beginning of the crisis in 2008, the employment rate among immigrants dropped almost 20 percentage points to 60 percent. Although natives' employment rate 


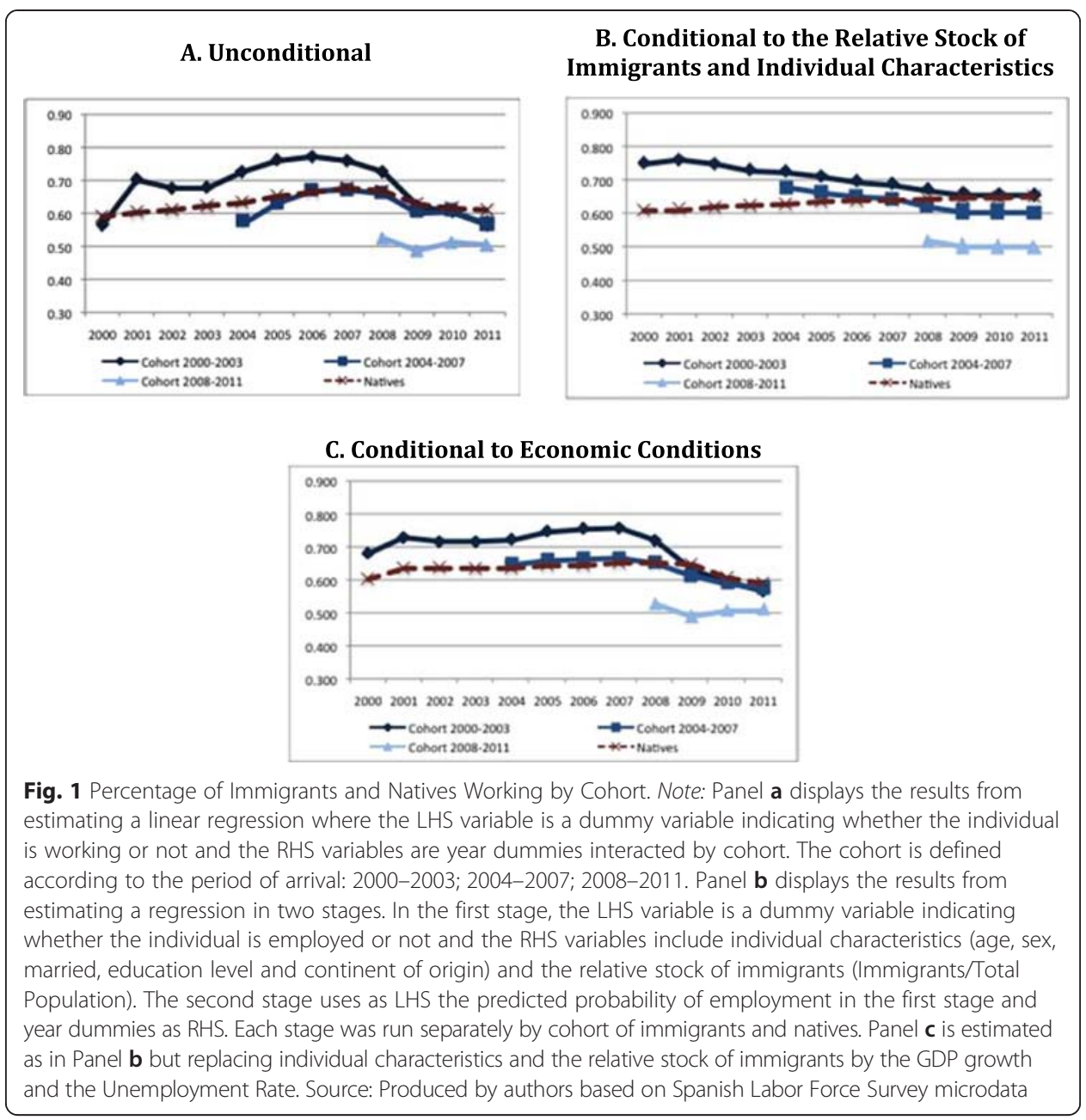

was also affected by the economic slowdown, the employment losses among immigrants were considerably larger than those of natives. As a result, after 2009 the native employment rate was higher than that of immigrants.

Panel a also shows that immigrants who arrived from 2004-2007 displayed a similar employment pattern to that of the first cohort. The major difference between the two cohorts is that the employment growth is more modest in the second cohort than the first cohort. A plausible explanation may be that they have been affected by the economic crisis within less than four years after arrival (as opposed to within eight years after arrival) and have thus had less time to progress in the labor market. Alternatively, it may well be that there has been a compositional change in the type of immigrant who has arrived in Spain over time. Fig. 1b, c explore the extent to which these alternative hypothesis are behind the differential employment patterns across cohorts.

Finally, the post-crisis cohort was clearly at a disadvantage in terms of employment integration relative to the older cohorts. First, the average employment rate at arrival for this cohort was around 50 percent, ranging between 5 and 10 percentage points lower than the 2004-2007 cohort and between 5 and 20 percentage points lower than the 2000-2003 cohort. Second, they did not experience the employment growth that was typically observed among immigrants within the first couple of years after arrival. 
Again two potential explanations emerge: differences in the characteristics of migrants or in the economic conditions at the time of arrival.

\subsection{Compositional differences}

Panel $\mathrm{b}$ in Fig. 1 plots the average employment rates for the three cohorts of immigrants and natives controlling for individuals' observable characteristics. Any differences between Panels a and b will reveal differences in employment rates due to individuals' characteristics.

Two interesting results emerge. First, the differential pattern between the 2000-2003 cohort and the 2004-2007 cohort observed in Panel a practically fades away in Panel b. This suggests that there has been a change in the composition of migrants across the two cohorts, with those in the latter cohort being at a relative disadvantage. Comparing characteristic differences across the two cohorts (shown in Table 1) reveals that the share of women and of immigrants from Eastern European countries is higher among the 2004-2007 cohort than the 2000-2003 cohort, and the share of Latin Americans (who are native Spanish speakers) has decreased.

Second, we observe that, in contrast with the other two cohorts, no changes are observed among immigrants arriving after 2007 suggesting that, for this cohort, quality composition is not behind its relatively lower labor market performance.

\subsection{Economic conditions}

Panel c plots the average employment rates for the three cohorts of immigrants and natives controlling for the economic conditions, namely the unemployment rate and the GDP growth. Any differences between Panels a and c will reveal that different cohorts of immigrants react differently to the business cycle. While the employment pattern observed in Panel c is smoother than that of Panel a, cohort differences remain. The 2000-2003 cohort outperforms the 2004-2007 cohort by 10 percentage points before the recession, and thereafter, these two older cohorts outperform the 2008-2011 cohort by 10 percentage points. It is interesting to note that immigrants arriving after 2007 are clearly at a disadvantage in terms of labor market performance despite being more college educated (shown in Table 1).

Table 1 Individual characteristics of migrants and natives

\begin{tabular}{lllll}
\hline & $2000-03$ cohort & 2004-07 cohort & 2008-11 cohort & Natives \\
\hline Age & $35.006(9.707)$ & $33.416(10.125)$ & $32.808(10.525)$ & $40.108(12.876)$ \\
Memale & $0.494(0.500)$ & $0.534(0.499)$ & $0.562(0.496)$ & $0.495(0.500)$ \\
HS Dropout & $0.562(0.496)$ & $0.506(0.500)$ & $0.495(0.500)$ & $0.586(0.492)$ \\
HS Graduate & $0.251(0.434)$ & $0.238(0.426)$ & $0.246(0.431)$ & $0.262(0.440)$ \\
College & $0.600(0.490)$ & $0.609(0.488)$ & $0.543(0.498)$ & $0.555(0.497)$ \\
Euro -15 & $0.150(0.357)$ & $0.152(0.359)$ & $0.211(0.408)$ & $0.184(0.387)$ \\
Rest of Europe & $0.064(0.244)$ & $0.074(0.262)$ & $0.093(0.290)$ & n.a. \\
Latin America & $0.214(0.410)$ & $0.277(0.448)$ & $0.209(0.407)$ & n.a. \\
Africa & $0.552(0.497)$ & $0.471(0.499)$ & $0.480(0.500)$ & n.a. \\
Other Continents & $0.144(0.351)$ & $0.148(0.355)$ & $0.169(0.375)$ & n.a. \\
\hline
\end{tabular}

Means and Standard Deviations (in parentheses) are for the period 2000-2011 Source: Produced by the authors using the Spanish Labor Force Survey microdata 


\subsection{Subgroup analysis}

Figures 10 to 12 in the Appendix show immigrants' employment assimilation trends by their socio-demographic characteristics such as education level, sex, age and country of origin. Figure 10 shows that having more than a high school diploma, for example, seems to have insulated immigrants somewhat from falling employment after 2008. But prior to the onset of the recession, employment outcomes for lower educated immigrants and those with post-secondary education were quite similar. Figure 11 also shows that gender has an impact. Across cohorts, men entered the labor market with higher employment rates, although women had larger gains over time. Women also appeared to maintain employment better than men during the recession. Despite an almost 20 percentage point advantage over female immigrants in 2007, employment among immigrant men declined to almost equal that of immigrant women in the first two cohorts by 2010. Finally, Fig. 12 shows that there are also clearly different employment patterns among immigrants by country of origin. EU-15 immigrants, for example, maintained a very stable employment rate across cohorts and throughout the observed period. Immigrants from other European countries, however, initially showed a strong trend of assimilation, but then saw their employment rates fall after the onset of the recession. Latin Americans experienced a similar employment pattern while Africans, who have consistently had the lowest employment rates, also saw a decline in their employment across cohorts.

\section{Immigrants' upward mobility}

Securing employment is, of course, not the sole measure of successful integration into the labor market. Immigrants who find work but become stuck in low-paid, insecure jobs remain at risk of marginalization and exclusion. It is therefore also important to ask whether immigrants are able to make their way into more secure, higher skilled jobs after several years in the labor market. To explore this, this section first analyzes the proportion of migrants in vulnerable positions, such as those out-of-employment (including both unemployment and out of the labor force) or those in the lowest skilled jobs. Second, it studies how the proportion of immigrants working in jobs requiring different types of skills (low, medium and high) or not working varies with years since arrival. Finally, we consider the impact of immigrants' individual characteristics on their occupational trajectories and evaluate the extent to which the pathways into middle-skilled work for immigrants hold up for those who lack high-level educational qualifications. The analysis is done by cohort of arrival.

Figure 2 plots the average proportion of immigrants in the lowest-skilled jobs and out-of-employment over the 2010-2011 period. ${ }^{3}$ Forty-one percent of immigrants in the first two cohorts were out-of-employment during this period, and the proportion rose to 49 percent of those in the most recent cohort. In comparison, over the same period, 39 percent of natives were out-of-employment.

In addition, between 19 and 23 percent of immigrants from these three cohorts were employed in low-skilled jobs, raising clear concerns about the precariousness of their economic situation in Spain. This concentration of immigrants in low-skill jobs is not observed among natives, among whom only 6 percent are in low-skilled work. Consistent with this, Fernández and Ortega 2008, and Sanromá et al. 2009 have also highlighted the predominance of over-education among immigrants in Spain. Altogether, close to 70 percent of migrants from the 2008-2011 cohort were either out-of-employment or in low-skilled jobs during the 2010-2011 period. While this share decreases with years in 


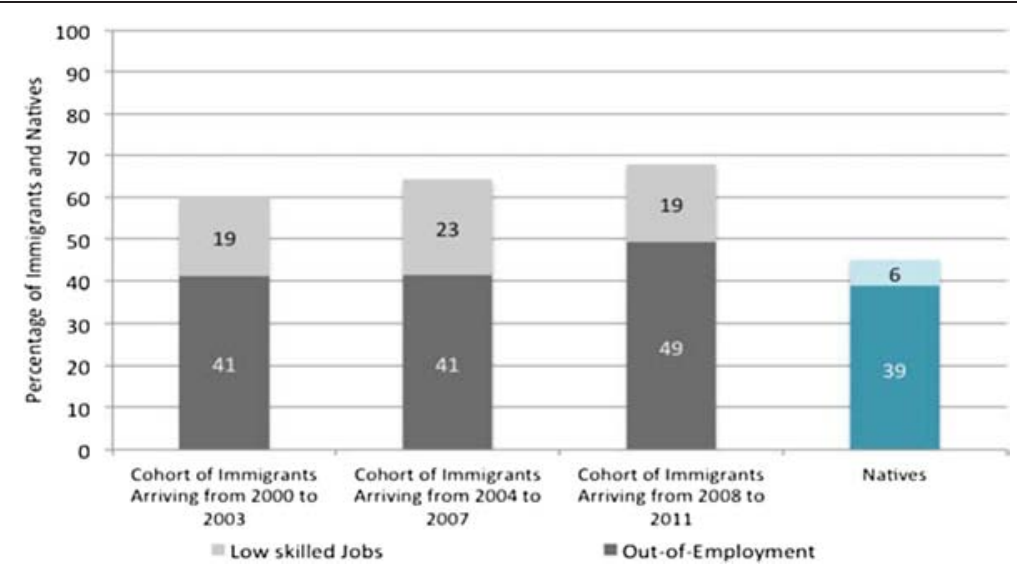

Fig. 2 Proportion of Immigrants and Natives in Spain who are Out-of-Employment or in the Lowest-Skilled Jobs, 2010-11. Notes: Lowest-skilled jobs are defined as International Standard Classification of Occupations (ISCO) code 9: Elementary Occupations. "Elementary occupations consist of simple and routine tasks which mainly require the use of hand-held tools and often some physical effort." Out-of-employment includes both unemployment and being out of the labor market. Source: Produced by the authors using Spanish Labor Force Survey micro-data

the country, it remains far from insignificant as it represents as much as 55 and 63 percent of immigrants from the 2000-2003 and the 2004-2007 cohorts, respectively. While low-skilled work is an essential part of the economy, a lack of upward mobility from low-skilled work to more stable forms of employment implies an overall precarious situation even for employed migrants, and one that persists over time. This level of precariousness among newly immigrants gains special relevance when compared to that of natives.

As Fig. 2 is an average over the 2010-2011 period, one may wonder how these percentages vary with years since arrival. This is shown in Fig. 3. Focusing first on the 2000-2003 cohort in Fig. 12, we observe that at arrival as many as 40 percent of immigrants are not employed. However, they quickly move into low- and medium-skill jobs within 3 to 5 years after arrival. As such, the proportion of immigrants out-of-employment drops almost by half from 40 percent to close to 20 percent. Similarly, Fig. 12 also shows that immigrants undergo a rapid adjustment within the first 3 to 5 years after arrival, moving first into low-skilled jobs and later on out of low-skill jobs towards medium-skilled ones. Nonetheless, Fig. 12 reveals a striking change in trends in the fifth year after arrival, which for those who arrived in Spain in 2003 represents the year 2008. As the Great Recession hits the Spanish economy in 2008, the share of out-of-employment immigrants soars from 20 percent to over 40 percent, and the proportion of immigrants working in medium-skill jobs drops from over 40 percent to 30 percent. Similarly, the proportion of immigrants in low-skill job, which had began to decline as migrants were finding higher skilled jobs that better matched their human capital endowment, continues to fall reflecting that, with the worsening of the economy, migrants are losing low-skill jobs. In contrast, the share of migrants in high-skilled jobs remains stable around 8 percent, unaffected by the economic conditions. Figure 3b, c show the results for the other two cohorts. The patterns follow closely those observed for the 2000-2003 cohort.

How robust are the pathways into middle-skilled work for immigrants who lack high educational level? To explore this, Fig. 3d replicates Fig. 3a using only migrants who have at most a high-school degree. As those represent about 85 


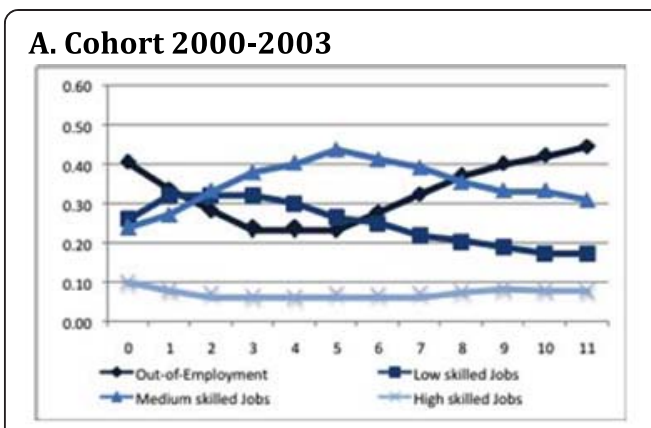

\section{Cohort 2008-2011}

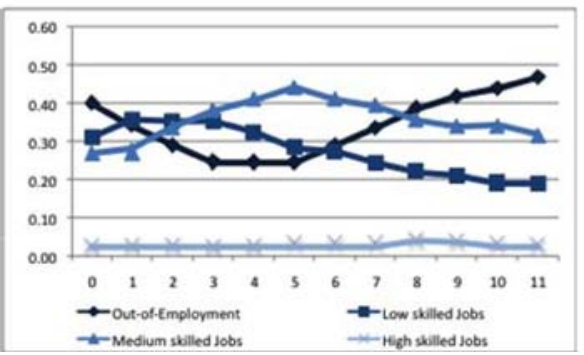

\section{B. Cohort 2004-2007}

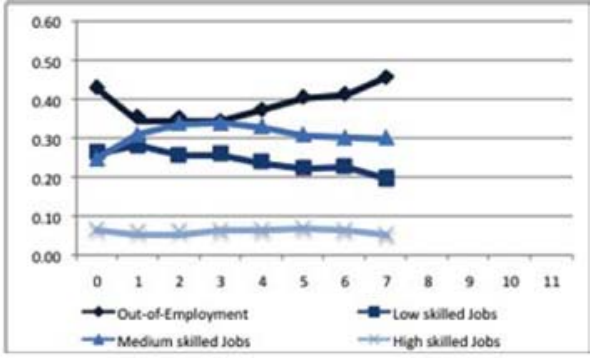

D. Cohort 2000-2003 - Conditional to having at most a high-school degree

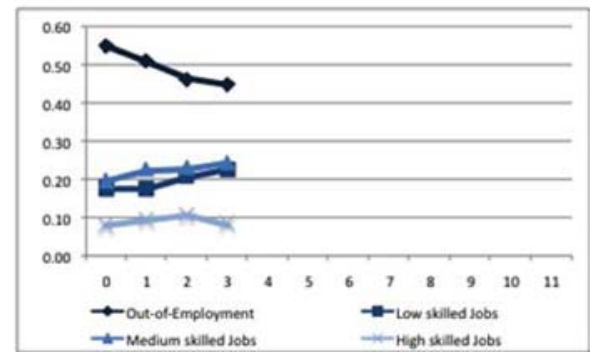

Fig. 3 Proportion of Immigrants Out-of-employment or in the Lowest skilled jobs by Cohort and Years after Migration. Notes: Elaborated by the authors based on micro data from the Spanish LFS. Lowest skilled jobs defined as ISCO code 9. Out-of-employment includes both unemployment and out of the labor market

percent of migrants it ought not to be a surprise that both figures are extremely similar. The major difference is the proportion of migrants in high-skilled jobs, which is now close to 3 percent (instead of close to 8 percent). Thus, we can conclude that assimilation into medium-skilled jobs among low-skilled migrant workers occurs in Spain. This finding is similar to that of Rodríguez-Planas 2012, who finds that "within the first few years after arrival, immigrants with a highschool degree or less first move from "not working" to "non-qualified" jobs. However, after 3 to 4 years after arrival, they begin to shift out of "non-qualified" jobs towards "qualified blue-collar" occupations."

\section{Sectors in which immigrants work}

While immigrants in Spain may have had little difficulty entering employment prior to the recession, many found work in sectors with a high degree of insecurity or little room for upward progression. Considering in which sectors immigrant workers are concentrated will help us understand which types of employment offer the best chances of movement into more secure, higher skilled jobs for immigrants.

Figure 4 shows the proportion of each sector that is filled by immigrant or native workers. While immigrants represent less than 10 percent of workers in most sectors and as little as 2 percent in the public sector, they represent 21 percent in "other services," which include domestic services. Three other sectors worth mentioning are construction; agriculture, forestry, and fishing; and wholesale and retail trade; in which immigrants represent approximately 9 percent of the workforce. These findings are consistent with previous studies that have found high levels of segregation of immigrant workers in the construction, food preparation and serving, and domestic services 


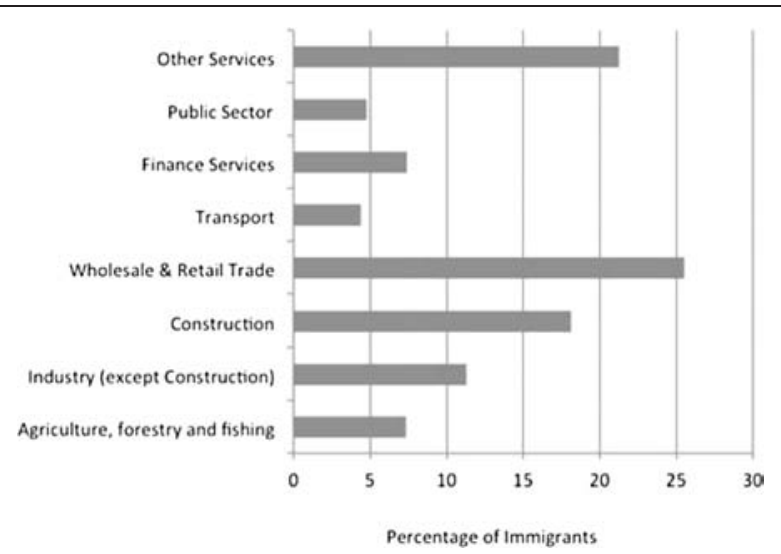

Fig. 4 Proportion of Immigrant Workers by Sector, 2010-11 Source: Produced by the authors based on Spanish Labor Force Survey microdata

sectors (Sanromá et al. 2009; and Gonzalez and Ortega 2010). The high proportion of immigrants in these sectors could be explained by the growth of the construction, tourism, and personal service industries in Spain during this period, together with poor government regulation of immigration (Rodríguez-Planas 2012).

Table 2 also reveals that those sectors with a higher concentration of immigrant workers have also a lower proportion of permanent contracts, suggesting that migrants are concentrated at the bottom of the occupational-skill spectrum. For instance, the proportion of permanent contracts in sectors with a predominance of immigrants ranges between 20 and 50 percent. In contrast, in sectors in which natives are concentrated, the percent of permanent workers is over 60 percent. These results are consistent with those found by Fernández and Ortega 2008, who find that the incidence of temporary contracts is much higher for newly arrived male immigrants than for comparable natives.

Another form of flexible work arrangement is part-time work, which in Spain has traditionally been a second-best job (Fernández-Kranz and Rodríguez-Planas 2011). As a consequence, part-time work in Spain is highly involuntary-as many as one fourth of part-time worker in Spain would prefer to work full-time if they could find such a job. Table 2 reveals that part-time work is more prevalent in finance services, other services, and trade sectors. Of these three sectors, two are sectors with an above average concentration of immigrants.

On average, job tenure is lowest in construction, trade, finance services and other services, which are also sectors with a high concentration of migrants (with the exception of finance services). Similarly, low-skilled jobs are concentrated in agriculture, forestry and fishing, construction, trade, and other services, again sectors with a high proportion of immigrants. In addition, the proportion of immigrants employed in jobs with less-desirable working conditions is higher than that of natives in each sector. For instance, the share of workers under a fixed-term contract in construction is 9 percentage points higher among immigrants than natives, and the share of workers in part-time work in trade is 7 percentage points higher for immigrants than natives. Overall then, the sectors under discussion-including services, construction and trade-contain the most precarious types of employment for immigrant workers. 
Table 2 Immigrant and natives' job characteristics by sectors

\begin{tabular}{|c|c|c|c|c|c|c|c|c|c|}
\hline & & Agri-culture, Forestry, and Fishing & Industry (except construction) & Construction & Trade & Transport & Finance services & Public sector & Other services \\
\hline \multirow[t]{2}{*}{ Percent with Permanent Contracts } & Natives & 18 & 69 & 35 & 49 & 61 & 63 & 75 & 53 \\
\hline & Immigrants & 23 & 52 & 26 & 46 & 53 & 50 & 44 & 52 \\
\hline \multirow[t]{2}{*}{ Percent with Full-Time Jobs } & Natives & 94 & 97 & 99 & 91 & 96 & 89 & 92 & 71 \\
\hline & Immigrants & 92 & 96 & 97 & 84 & 92 & 76 & 75 & 63 \\
\hline \multirow[t]{2}{*}{ Tenure (in Months) } & Natives & 153.3 & 128.5 & 80.5 & 101.8 & 126.7 & 100.8 & 145.3 & 89.4 \\
\hline & Immigrants & 20.3 & 30.4 & 22.4 & 25.4 & 30.8 & 29.9 & 27.2 & 28.0 \\
\hline \multirow[t]{2}{*}{ Percent in Low-Skilled Jobs } & Natives & 24 & 9 & 15 & 10 & 7 & 18 & 7 & 39 \\
\hline & Immigrants & 79 & 17 & 30 & 19 & 13 & 45 & 12 & 74 \\
\hline \multirow[t]{2}{*}{ Percent in Medium-Skilled Jobs } & Natives & 70 & 70 & 74 & 60 & 73 & 30 & 33 & 39 \\
\hline & Immigrants & 20 & 73 & 67 & 72 & 63 & 26 & 37 & 22 \\
\hline \multirow[t]{2}{*}{ Percent in High-Skilled Jobs } & Natives & 5 & 21 & 11 & 30 & 20 & 52 & 59 & 23 \\
\hline & Immigrants & 1 & 10 & 3 & 9 & 24 & 29 & 51 & 4 \\
\hline
\end{tabular}


Figure 5 shows whether the share of immigrants in lowest skill jobs changes with time spent in Spain across. We observe that except for construction, the share of immigrants in low-skilled jobs in trade, industry and other services remains flat. In contrast, there is a downward trend in the share of immigrants in low skilled-jobs in construction suggesting that in this sector immigrants may be more able to progress into more skilled jobs over time. While this trend starts well beyond 2008, it is important to note that after the crisis it may be due to the fact that employers prefer letting immigrants go before laying off natives.

Figure 6 shows how the share of the immigrant workforce from the first cohort participating in each sector has changed overtime. It is interesting to note that there is an overall positive trend in transport, public sectors, and trade. In addition, prior to the recession in 2008, immigrants flow from agriculture and other sectors to construction. However, this pattern comes to a halt in 2008 when it becomes clear that construction has been hit by the recession. From there on, the share of immigrants in agriculture stabilizes, suggesting that immigrants fled from construction to agriculture (in addition to the other sectors for which an upward trend has already been mentioned).

Segregation into sectors with less-desirable characteristics is more intense for some immigrant groups than others. Figure 7 suggests that less educated immigrant workers tend to be more represented in sectors with poor job characteristics (such as construction and other services) than more educated immigrants. Interestingly though, even immigrants with higher levels of education remain concentrated in these sectors. This suggests that more education may have a lower pay-off for immigrants in terms of occupational mobility than for is the case for natives.

Immigrant women are also clearly more likely than men to be employed in poorer sectors. Almost 40 percent of immigrant women are employed in the other services sector, which has a larger share of low-skilled jobs than any other sector (Fig. 8). Men, by contrast, are more likely to be employed in the construction sector. As the construction sector was particularly hard hit by the economic crisis,

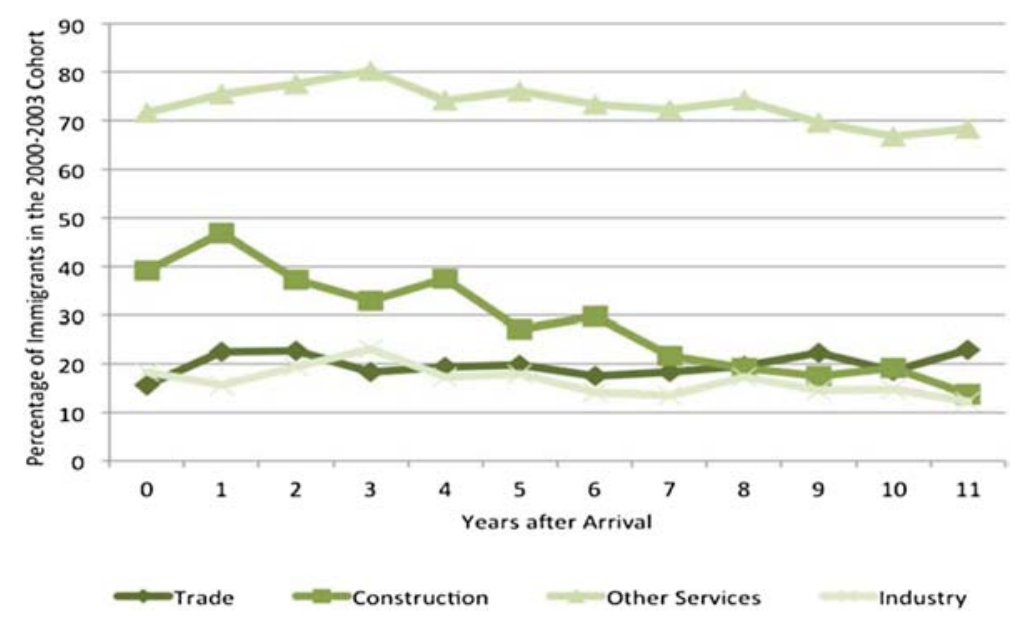

Fig. 5 Share of 2000-03 Immigrant Cohort in Lowest-Skilled Jobs by Sectors, 2000-11. Note: Lowest skilled jobs defined as ISCO code 9. Source: Produced by the authors based on Spanish LFS microdata 


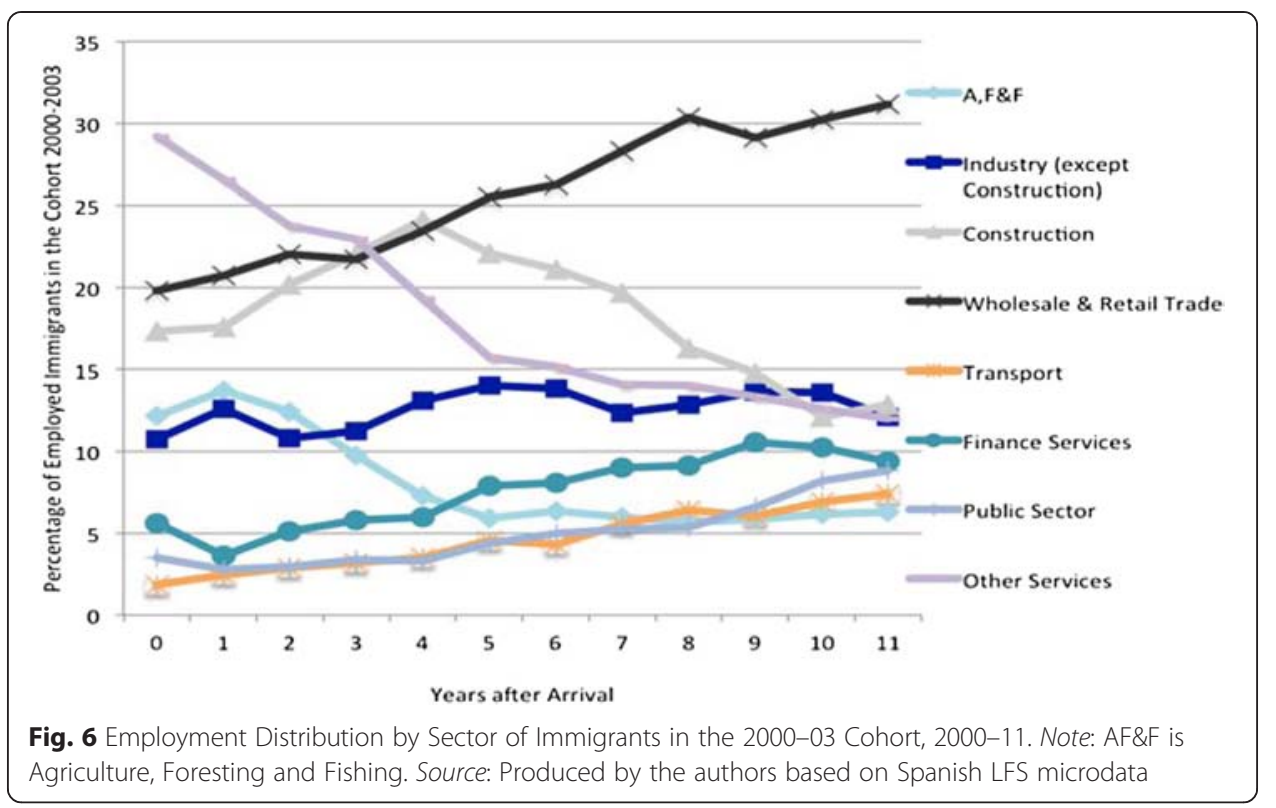

the high proportion of immigrant men employed in construction explains to some extent why immigrant men saw a larger drop in employment after 2008 than women.

Finally, immigrants' distribution among the sectors differs according to country of origin. Figure 9 shows that while EU-15 immigrants are employed in approximately the same sectors as natives-with the exception of being underrepresented in the public sector-, Latin American, other European, and African immigrants are all highly overrepresented in other services, construction, and agriculture-sectors with some of the highest shares of low-skilled jobs.

\section{Conclusions}

During most of the last decade, newly arrived immigrants in Spain had no trouble finding jobs and quickly moved from low-skilled to medium-skilled jobs. The booming

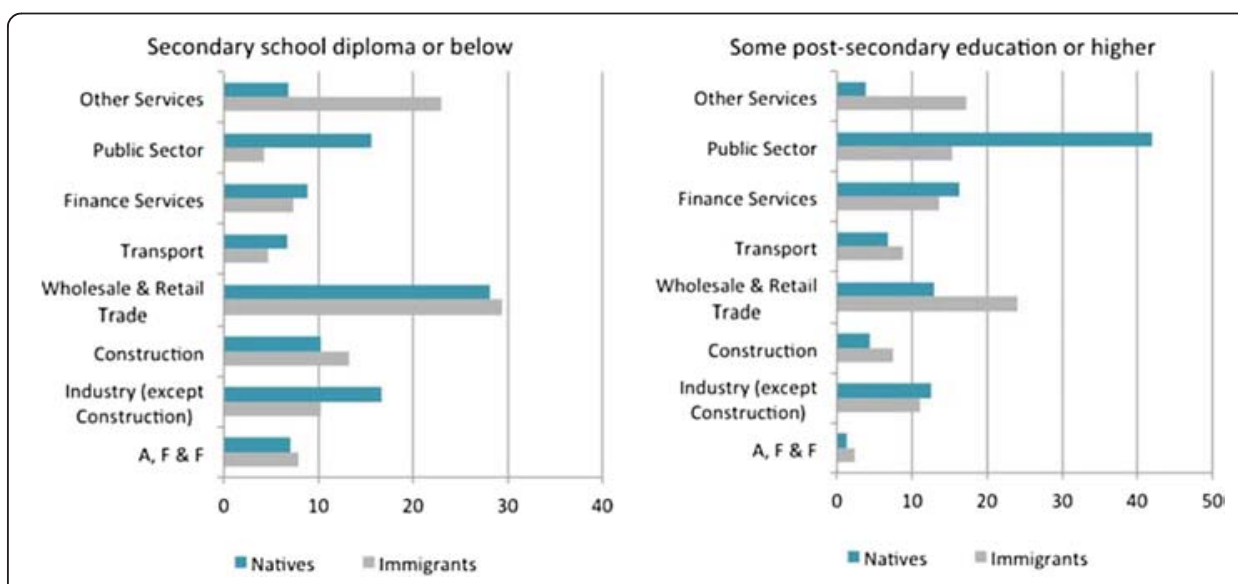

Fig. 7 Distribution of Immigrant and Native Workers by Sector and Education level, 2010-11. Source: Produced by the authors based on Spanish Labor Force Survey microdata 


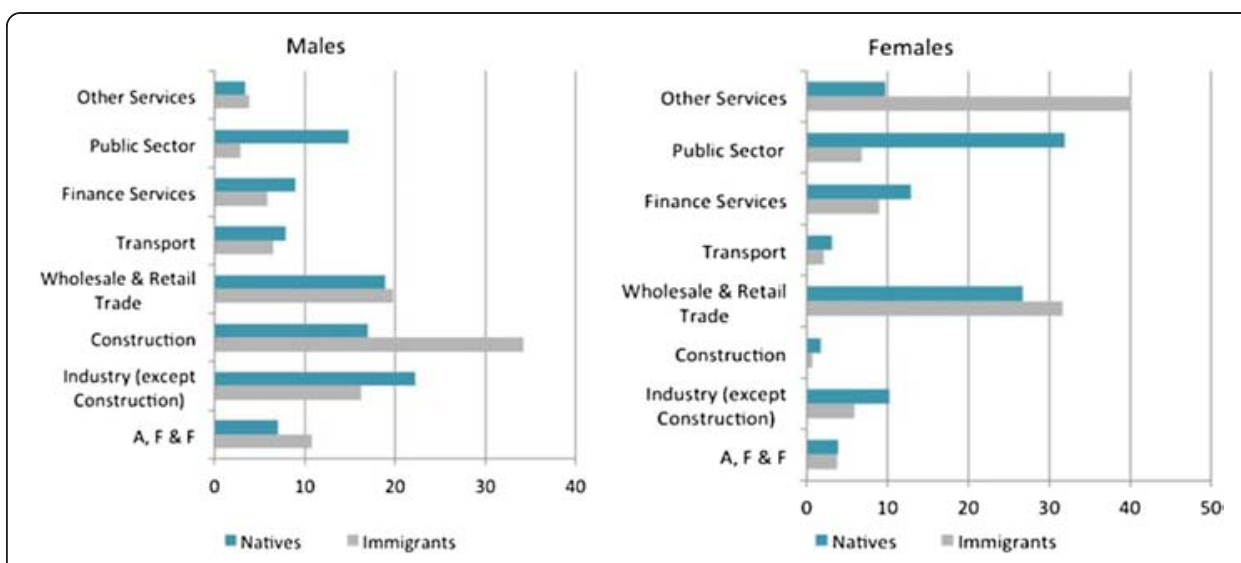

Fig 8 Distribution of Immigrant and Native Workers by Sector and Gender, 2010-11. Source: Produced by the authors based on Spanish Labor Force Survey microdata

economy and excess demand for low-skilled workers in construction, trade, and other services sectors enabled easy integration into the labor market for most immigrants. Immigrants who arrived prior to 2008 seemed able to move quickly into employment and then from low-skilled to medium-skilled jobs within the first 3 to 5 years after arrival. But for many their economic situation in Spain has remained precarious. On average, one quarter of immigrants who arrived prior to the recession work in low-skilled jobs (compared to only 8 percent among natives), and the situation is worst for women and for migrants from Africa. Most immigrant workers have tended to be concentrated in construction, trade, agriculture, farming and fishing, and other services-all of which have a larger proportion of fixed-term contracts

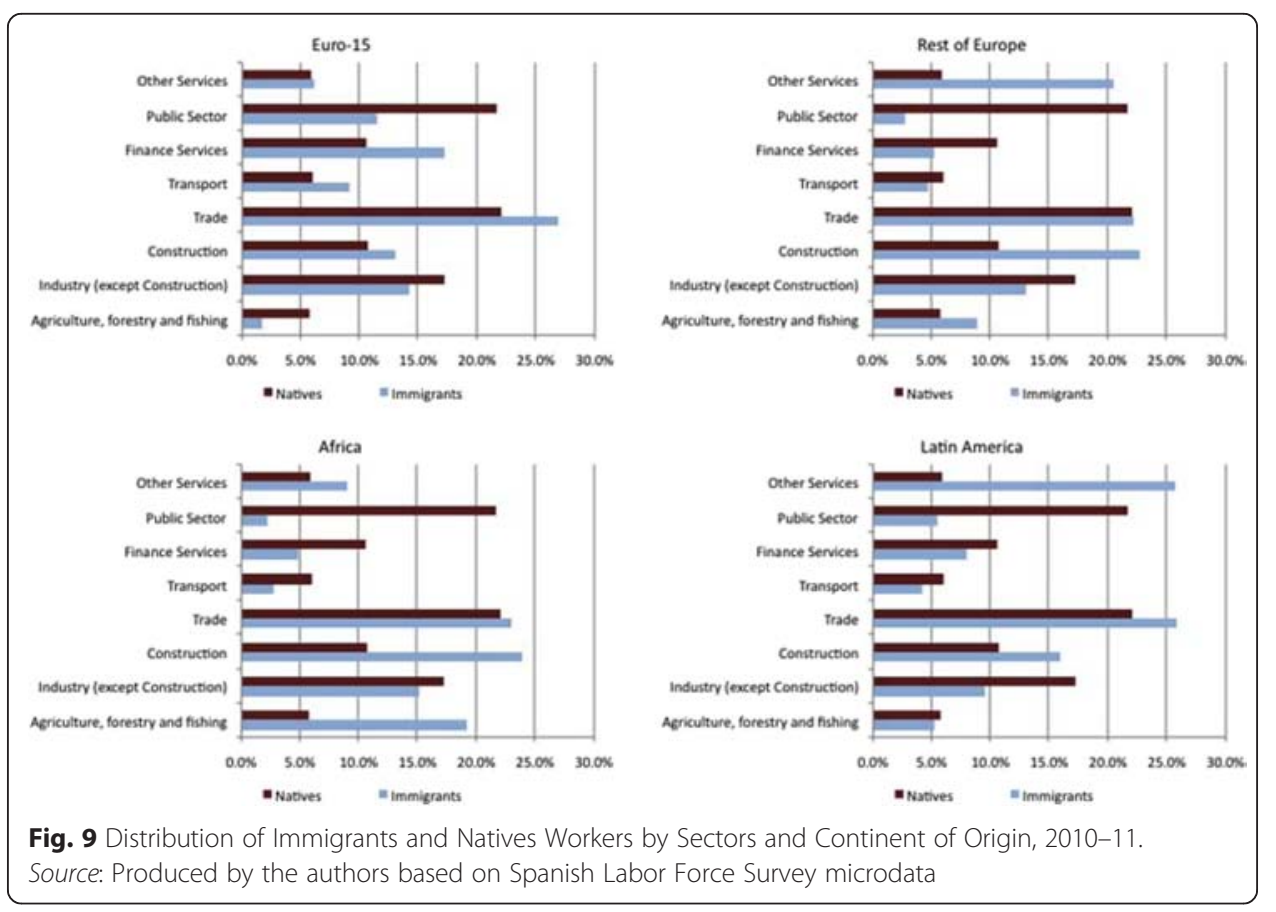


and part-time jobs. In addition, these sectors also have a prevalence of low-skilled work and, on average, shorter job tenure.

Given their precarious situation in the labor market and overrepresentation in sectors that were particularly hard hit during the economic crisis, the recession has had a clear, negative impact on immigrant patterns of employment in Spain. As the economy shed low- and medium-skilled jobs, many immigrant workers moved back into unemployment or exited the labor market entirely. Only those in high-skilled positions appeared to weather the crisis with some success. The first immigrant cohort to arrive after the beginning of the recession had less luck. This group's greater difficulty entering the labor market is likely due to both the decreased demand for low-skilled workers caused by the recession and an increase in the share of non-native Spanish speakers and women among more recent immigrant flows.

The long-term implications of the recession for immigrant workers in Spain remain to be seen. In the long run, Spain will need immigrants to cover labor shortages because of its ageing population and the emigration of people to other countries. As a result of the recession many skilled natives (i.e. engineers, business men and architects) are leaving the country to find better job opportunities in Western Europe, the US or the booming economies in Latin America. Analysts are not very optimistic about the recovery of the Spanish economy, thus most of those emigrant workers are not likely to return. In turn, skilled immigrants, with lower reservation jobs, are good candidates to cover those vacancies. In addition, the ageing population will increase the demand for elderly care services. The Spanish experience suggests that immigrants, in particular women, cover these vacancies, at least during their first years upon their arrival to Spain.

\section{Endnotes}

${ }^{1}$ Free-entrance of foreigners as tourists together with a lax implementation of immigration laws and several generous amnesties that have granted legal residence to illegal immigrants (in 1985, 1991, 1996, 2000, 2001, and 2005) have made Spain an attractive destination for both legal and illegal immigration flows-see AmuedoDorantes and de la Rica 2005, 2007; Dolado and Vázquez 2007; and Izquierdo et al. 2009.

${ }^{2}$ The LFS includes both legal and illegal immigrants, in contrast with alternative datasets that only cover legal residents, such as administrative data from Social Security Records or the Wage Survey Structure. That said, under-reporting of illegal immigrants is likely (as the LFS is voluntary, in contrast with the Census, which is mandatory), and it is not possible to identify legal status in the LFS data.

${ }^{3}$ Lowest-skilled jobs are defined as International Standard Classification of Occupations (ISCO) code 9: Elementary Occupations. "Elementary occupations consist of simple and routine tasks which mainly require the use of hand-held tools and often some physical effort." See International Labor Organization, "Major Group 9: Elementary Occupations," September 18, 2004, www.ilo.org/public/english/bureau/ stat/isco/isco88/9.htm. 


\section{Appendix}

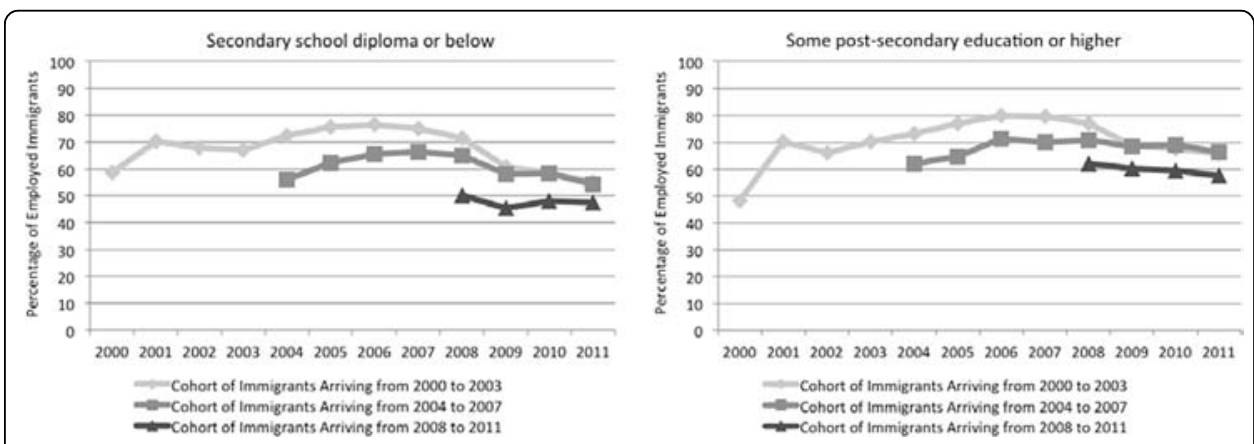

Fig. 10 Immigrant Employment Trends in Spain by Education Level, 2000-11. Source: Produced by authors using Spanish Labor Force Survey microdata
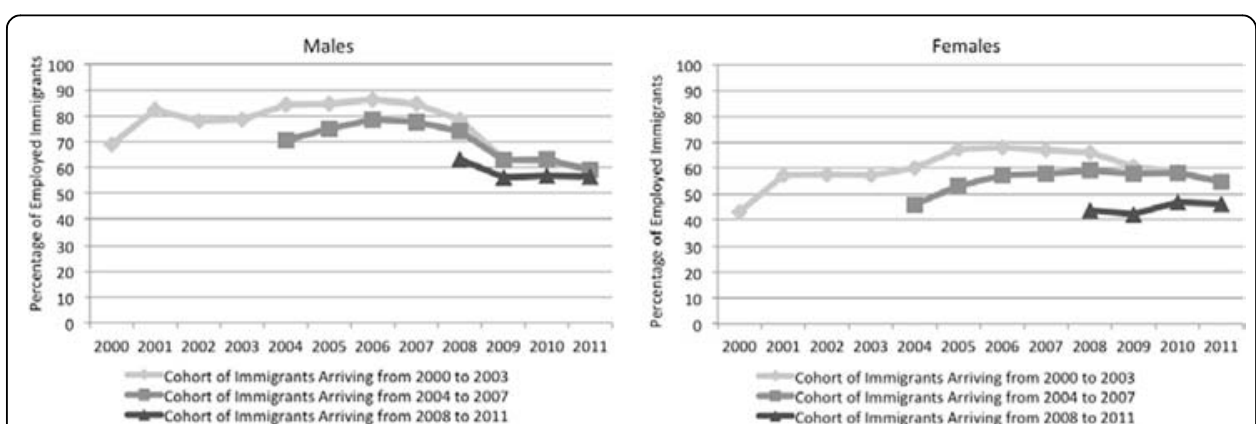

Fig. 11 Immigrant Employment Trends in Spain by Gender, 2000-11. Source: Produced by authors using Spanish Labor Force Survey microdata.

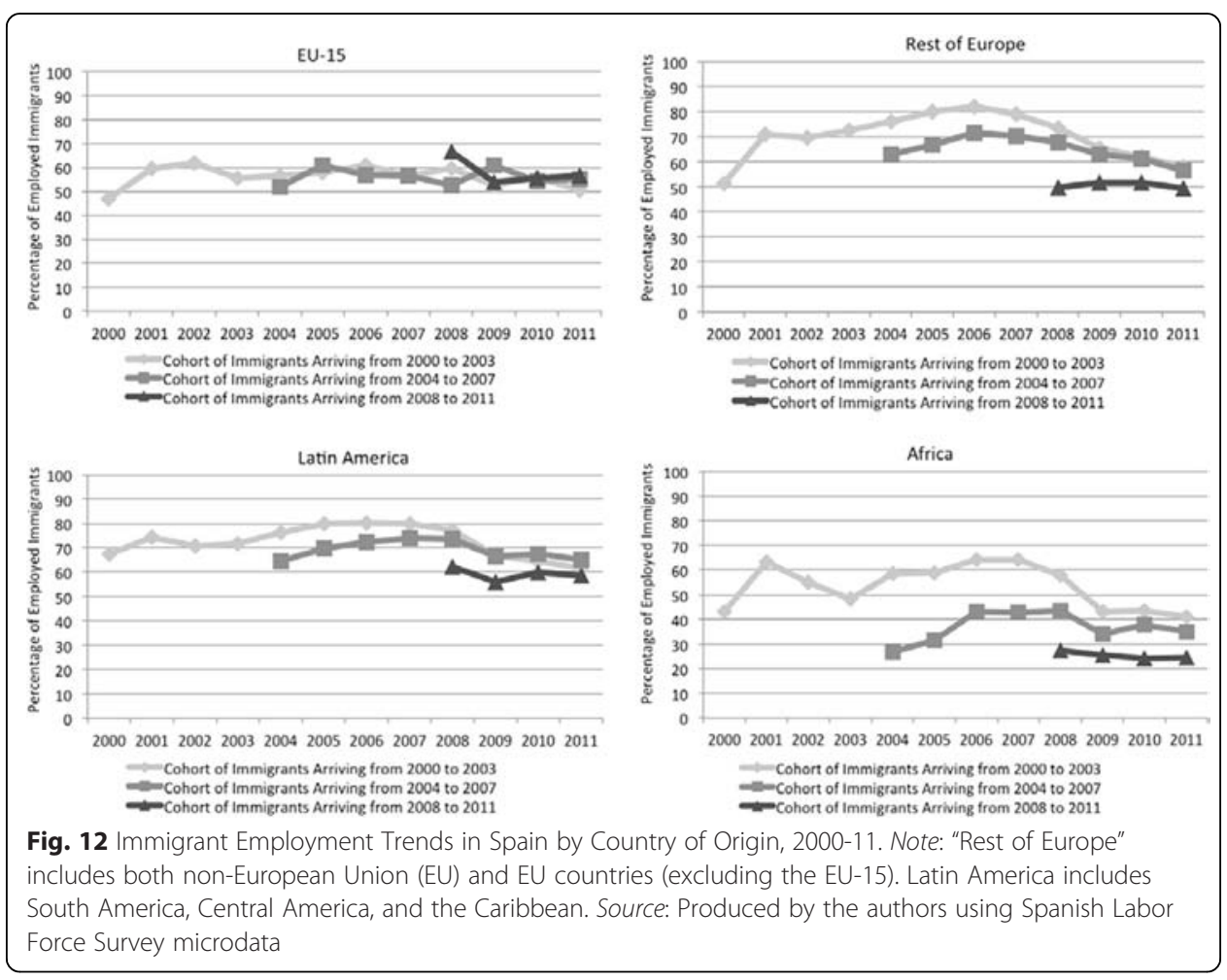




\section{Competing interests}

The IZA Journal of Labor Policy is committed to the IZA Guiding Principles of Research Integrity. The authors declare that they have observed these principles.

\section{Acknowledgements}

This paper emerges from a research report carried out to the Migration Policy Institute as part of a research project funded by the European Union and conducted in collaboration with the International Labour Office. The authors would like to express their thanks to the Migration Policy Institute.

Responsible editor: Juan F Jimeno

\section{Author details}

${ }^{1}$ City University of New York (CUNY), Queens College, New York, USA. ${ }^{2}$ ZZA, Bonn, Germany. ${ }^{3}$ IAE-CSIC, Barcelona, Spain

Received: 28 November 2014 Accepted: 4 January 2016

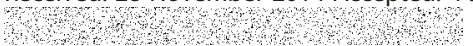

\section{References}

Amuedo-Dorantes C, De la Rica S (2005) Immigrants' Responsiveness to Labor Market Conditions and its Implications on Regional Disparities: Evidence from Spain. Discussion Paper No. 1557, Bonn, Germany

Amuedo-Dorantes C, De la Rica S (2007) Labor Market Assimilation in Spain. British Journal of Industrial Relations 45(2):257-84

Dolado JJ, Vázquez P (eds) (2007) Ensayos sobre Los Efectos Económicos y las Políticas de la Inmigración: Panorámica y Reflexiones. Fundación de Estudios de Economía Aplicada (Fedea), Madrid

Fernández C, Ortega C (2008) Labor Market Assimilation of Immigrants in Spain: Employment at the Expense of Bad Job-Matches? Spanish Economic Review 10(2):83-107

Fernández-Kranz D, Rodríguez-Planas N (2011) The Part-Time Penalty in a Segmented Labor Market. Labour Economics 18(5):591-606

Gonzalez L, Ortega F (2010) How Do Very Open Economies Absorb Large Immigration Flows? Evidence from Spanish Regions. Labour Economics 18:57-70

Izquierdo M, Lacuesta A, Vegas R (2009) Assimilation of Immigrants in Spain: A Longitudinal Analysis. Labour Economics 16(6):669-78

Rodríguez-Planas N (2012) Wage and Occupational Assimilation by Skill Level. Migration Policy Lessons from Spain. IZA Journal of European Labor Studies 1:8

Rodríguez-Planas N (2013) Determinants of Immigrant's Cash-Welfare Benefit Intake in Spain. International Journal of Manpower 43(2):167-80

Sanromá E, Raúl R, Hipólito S (2009) Immigrant Wages in the Spanish Labor Market: Does the Origin of Human Capital Matter? IZA Discussion Paper No. 4157, Bonn, Germany

Submit your manuscript to a SpringerOpen ${ }^{\circ}$ journal and benefit from:

- Convenient online submission

Rigorous peer review

- Immediate publication on acceptance

- Open access: articles freely available online

High visibility within the field

- Retaining the copyright to your article 